\title{
Developing Student Value Attitude to Reasoning in Mathematics and its Integration into Teaching
}

\author{
M. Rodionov \\ Penza State University \\ Penza, Russia
}

\begin{abstract}
Reasoning or argumentation abilities are the most valuable contribution of Math as a science to human culture. That is why the issue of developing reasoning abilities is becoming very important at school. There are different approaches to the analysis of the interconnection of the deductive component of mathematical education and pupils' "motivational mechanisms". Many scientists are sure Math syllabus must be discussed from the motivational point of view. So it is essential for teachers to encourage pupils to master deductive reasoning abilities. There are two main conditions that influence the development of value attitude to reasoning in mathematical activity. To meet the conditions it is necessary to diagnose pupils reasoning and reflexive abilities and consider them at every level of teaching reasoning.
\end{abstract}

\section{Introduction}

The role of reasoning/argumentation in the school Mathematics curriculum is finely expressed by George Polya [5]. He considers reasoning abilities the most important contribution of Math as a science to human culture. The pupil who has not been impressed by the process of reasoning misses one of the key intellectual experiences. Thus, it is necessary to encourage pupils to realize that.

Based on Thorndike's classical methods [9], studies were conducted in several schools in Penza, Russia and across Trinidad and Tobago. The results show that more than half of high school students respond negatively towards logical proving. Many students expressed the view that a logical proof approach denies or diminishes the possibility for an intuitive solution to the problem or task. This demonstrates that the skills needed to prove theorems are formed irregularly in mathematical studies. These findings support the case for a re-evaluation of existing theoretical and practical approaches to proof studies, from a general standpoint.

There are different approaches to the analysis of the interconnection of the deductive component of mathematical education and pupils" "motivational mechanisms". On the one hand, it is important for the Math syllabus to be discussed from the

\author{
Z. Dedovets \\ The University of the West Indies \\ Trinidad and Tobago
}

motivational point of view. On the other hand, it is essential for pupils to be encouraged to master deductive reasoning abilities.

The choice of the Math syllabus depends on the compliance of the deductive reasoning consistency/ logicality with the intellectual and motivational potential of pupils personality. The question of a certain level of consistency at a certain cognition level presupposes a harmonic combination of logic and intuition [3]. That provides an opportunity to include the deductive component of Math activity into the pupils' personal system of values in accordance with the academic context. At school such combination is expressed by pupils`ability to define notions, concepts and to prove theorems logically and should be based on pupils` visual and intuitive views.

The question of optimal balance of consistency and visual aids in describing the Math content has not been solved yet. Different indicators have been proposed to regulate consistency. Among them: 1) the importance of the term or notion and its frequency in the course of Math;2) pupils`age; 3) the subject itself (geometry or algebra); 4) compliance with the acquired by pupils set of notions.

In today's system of education the question of where to draw the line between the two positions mentioned above is still the prerogative of the author of the textbook or the teacher who uses this textbook.

\section{The three levels of reasoning consistency}

To define the levels of reasoning consistency and corresponding stages of educational process teachers should take into account motivation and importance of reasoning for pupils. There are three levels of mathematical reasoning consistency that correspond to three levels of pupils reflexive abilities $[1,4,6,8]$ :

- "reasoning for me" level (based on intuition)

- "reasoning for others" level (based on experience)

- "reasoning for me through reasoning for others" level 


\section{1. "Reasoning for me" level}

At this level the very term "to prove/to reason" means to pupils that it is necessary to do something to show and confirm the existence of an object or phenomenon. Pupils understand they have achieved some results but cannot say what methods or techniques they used.

The explanation of actions is substituted by stating the sequence of arithmetic operations, measuring procedures or elementary geometrical constructions or "creating" some "artificial move" that assumes the result as a starting point.

For example, a fairly typical fifth-grader response to the question "How can I do this sum?" is either a reproduction of each step of doing the sum ("five plus six, then double the result") or if the situation is not quite familiar, an attempt to artificially select actions to get the intuitively predicted outcome. Such features of pupils`activity can be observed in the process of deductive reasoning when it is necessary to use general rules and definitions that have been inductively derived before. This activity reveals itself in using the rule they know quite well or in some actions that prove other alternative decisions to contradict "the common sense" (it is impossible to solve the equation by the dividing five to two because we will get a fractional number that is not right). So it is necessary to find an alternative decision.

The main reason for such a phenomenon is the dominance of visual thinking. Visual thinking follows some rules that differ from those of verbal thinking. Pupils grasp the idea (try to find a solution) without detailed analysis, frequently on the basis of some random connections. The conclusions are not expressed verbally. The process of thinking is just a swift change of images (spatial, sign, graphic, etc.). The result of the process (if there is any) is just a kind of a "mental picture".

For example, the "proof" of the Triangle Angle Sum Theorem at this level (see Figure 1) can be represented as moving the line AC parallel to itself to the point where this line passes through the point $\mathrm{B}$. In this case, all the angles of the triangle $\mathrm{ABC}$ "get together" at this point making a flat angle.

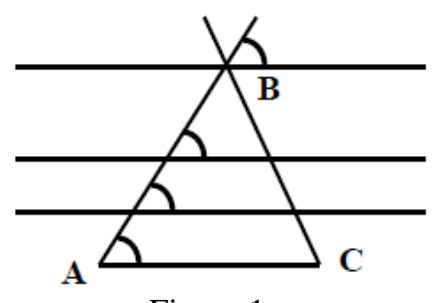

Figure 1.

Thus, at the first level the accuracy of the results is substituted by a simple check of the compliance of the intermediate and final results with pupils` visual and intuitive images. The process of reasoning (proving) is an involuntarily minimized act (or a sequence of acts) of transforming one visual image into some other format using the limited visual material. The inclination to use the deductive reasoning is determined by usual practice rather than understanding the importance of acquiring the skills of deductive reasoning.

It is useful to adopt special strategies to road-map the process; shifting students' attention from the subject of proving to the process of proving. During this transition the student will focus on the content while controlling the execution.

\section{2. "Reasoning for others" level}

At the second level pupils stop using deductive procedures automatically and realize the necessity to reconsider them. The first thing the pupil has to reconsider is in the external rather than in the internal environment. In other words, they do not associate the content of argumentation with the personality mechanisms. Therefore, they are interested in convincing the teacher and the classmates that their own statements are correct and useful rather than wishing to analyze the logical steps they used.

This level is transitional because pupils not only reproduce the learned patterns of argumentation but try to combine them to adjust to new circumstances. Pupils can voluntarily use statements (axioms by nature) and statements based on axioms though they may not be fully aware of the logical connections in them. The strengthening of the logical component occurs due to a closer link between verballysymbolic and visual components. Images are a means to stimulate deductive reasoning and to interpret the logical conclusions. Therefore, at the second level it is permissible to use "not quite mathematical" arguments various in depth and completeness as well as omit some steps which are intuitively evident for pupils.

Let us consider a well-known version of the proof of the Triangle Angle Sum Theorem as an example (see Figure 2).

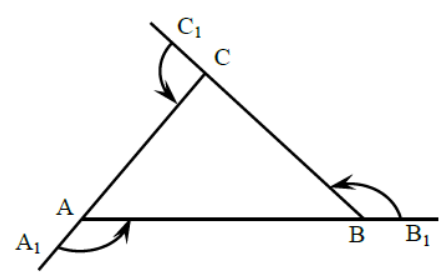

Figure 2.

Moving in a closed loop of the triangle $\mathrm{ABC}$ from point $\mathrm{A}$, before returning to the starting point we should make three turns that correspond to the angles adjacent to the angles of the triangle. As it is 
one complete revolution around the triangle the sum of the angles must be equal to $360^{\circ}$. We have

$$
\left(180^{\circ}-\alpha\right)+\left(180^{\circ}-\beta\right)+\left(180^{\circ}-\gamma\right)=360^{\circ},
$$

therefore $\alpha+\beta+\gamma=180^{\circ}$.

It is clear that despite the "transparency" and the simplicity of the proving it may not be considered logical enough in the conventional sense of logic as it implicitly relies on the statement that is logically equivalent to the conclusion of the theorem ("any triangle bypass on the plane is connected with $360^{\circ}$ "). However, this statement if considered at the level of "mental experience" due to its "tangibility" and "transparency" of transition from visual and intuitive to verbal means has a definite advantage in the terms of motivation, as practice shows.

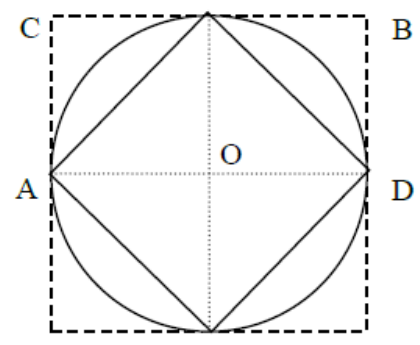

Figure 3.

Despite certain drawbacks in pupils' "argumentation tools" they can sort the qualities of the analytical and geometric objects, thus, providing a motivational basis for their further analysis and put them into practice.

\section{3. "Reasoning for me through reasoning for others" level}

The third level suggests that it is possible for pupils not only to understand the most essential connections in the process of mental activity but also the nature of this activity. At this level pupils are able not only to comment on the sequence of steps they take but go beyond "the original deductive field" answering the questions: "What are the premises that can help to draw a conclusion or deduce a formula?", "What statements can be made on basis of these premises?". The pupils can reflect the content of reasoning as well as control implementing their own deductive procedures.

Let us give the simplest example of the preparatory assignment promoting the development of school students' reflexive abilities [2].

Example: The square is in the circle. What it is bigger? (see Figure 3).

a) the area of the circle or the area of the square?

b) the doubled area of the square or the area of the circle?

c) the area of the square or half the area of the circle?

d) the area of the rectangle $\mathrm{ABCD}$ or the area of the circle?
It is necessary for the pupils to use deduction elements when answering these questions. To answer the first question the pupils only have to specify that the square occupies only a part of the circle and consequently its area is less than the area of the circle. To answer the second question it is necessary to go off the limits of the main configuration and describe the square. As the described square is twice the size of the first one and thus includes the circle, the doubled area of the initial square will be twice the area of the circle. Finally, the answers to the third and forth questions are considered direct consequences of the previous reasoning (with the use of the obvious facts: "halves of something equal are equal"; "something equal to the same thing is equal to each other").

It is essential to note that argumentation is used not to say that some mathematical facts and their qualities are true but justify the succession of steps of putting these facts to order. In other words, pupils begin to search for some common features and methods to be used when speaking about a great number of other mathematical laws and patterns. The ability to define the succession of stages/steps (due to the strengthening the role of conceptual thinking that can be observed at this level) does not mean full replacement of visual and intuitive forms by their logic equivalents. That implies mutual enrichment that is based on the reorganization of the mechanism of perceiving information. Such reorganization, first of all, suggests the change of the role of visual and intuitive tools which are considered factors stimulating and interpreting logic conclusions.

Acquisition of the above characteristics provides them with the ability to choose the necessary logic and heuristic means to achieve their academic goals and the ways to achieve them and to predict the future prospects. At this level pupils have an opportunity to points in reasoning and, therefore, to state what should be described fully while reasoning and what can be omitted.

In the Table 1 below we gave criteria together with related techniques that may most likely serve to initiate the development of systematic behavior in students for reasoning and proving.

When discussing the attributes of the equality of triangles the teacher have the students formulate their own attributes. Their searches for possible attributes lead to the formulation of three "new" attributes: two angles and the side opposite to one of the angles, two sides and an angle opposite to one of the sides and three angles. The last attribute is easily denied by a counterexample. The correctness of the first two is not established until sometime in the future. Unfortunately, attempts to prove their attribute using the analogy of proven attributes were unsuccessful. As a result the students come to the realization that 
Table 1.

\begin{tabular}{|c|c|c|c|c|c|c|c|}
\hline Methods & 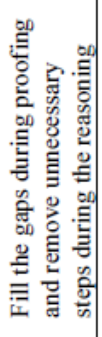 & 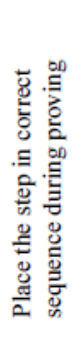 & 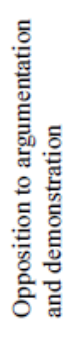 & 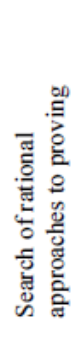 & 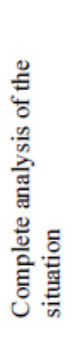 & 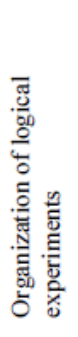 & 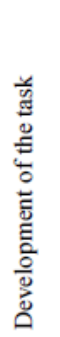 \\
\hline Argument completeness & + & + & + & + & + & + & \\
\hline Internal Locus Control & + & & + & + & + & & \\
\hline Variety of Choices & & & & + & & + & + \\
\hline Control of the long-term task & & + & & + & + & & + \\
\hline Focus on Task activity & + & + & + & + & + & + & + \\
\hline Wide spectrum of evaluation criteria & & & & + & + & + & + \\
\hline
\end{tabular}

their knowledge is incomplete. This serves as a long-term motivator during the study of topics in the future.

The first attribute formulated by students can be used as a starting point in the study of triangle angle theorem proofs. The second attribute (commonly known as the fourth property of equality in triangles) is realized when studying the construction of the triangle based on its three given elements. The construction of a triangle based on two given sides and an angle, which leads to two possible solutions (see Figure 4).

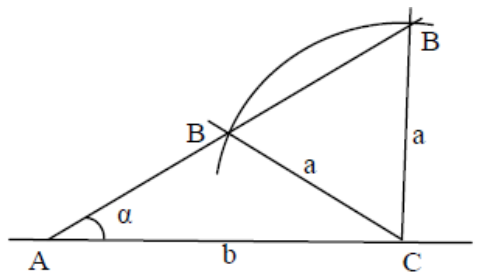

Figure 4.

A non-transparent solution stimulates research for additional conditions, which activates the fourth attribute. Congruency between angles at the vertex of triangle $\mathrm{B}$ and triangle $\mathrm{B} 1$ can be selected as an additional condition (both angles must be simultaneously obtuse, acute or right). Based on the above, and through various studies, it can be proven that the ability to establish and develop selfconsciousness (or habit) among students through conclusive reasoning can be established.

\section{Conclusions}

There are a lot of publications about the theory of teaching reasoning abilities. It is essential to note there are two main conditions that influence the development of value attitude to reasoning in mathematical activity.

1) Identifying the necessary level of consistency and useful methods of teaching;

2) Using stimulation tools that help to move up "the ladder of the levels".

In the arsenal of the methodical science, there is a large number of didactic techniques and systems promoting the solution of the specified task described in the paper. These didactic techniques are shown in the following Table 2 . It is necessary to note that the techniques of the lower levels can be used at higher levels (but not the other way) providing school students with training materials of the various degree of complexity for each case.

To meet the given conditions it is necessary to diagnose pupils` reasoning and reflexive abilities and consider them at every level of teaching reasoning abilities. As school practice shows, it is very difficult because of different levels of pupils' reflexive abilities. This difficulty can be partially overcome by appropriately combining reasoning statements that differ in the degree of complexity.

The first stage pupils can only use reasoning statements based on "common sense". But for older pupils these statements are just a preliminary stage of the perception of the proof and its structure as a whole. But the second stage corresponds to 
Table 2.

\begin{tabular}{|c|c|c|c|}
\hline $\begin{array}{l}\text { Stages levels of studying } \\
\text { theorems }\end{array}$ & 1 level & 2 level & 3 level \\
\hline $\begin{array}{l}\text { Motivation of studying } \\
\text { the theorem and } \\
\text { disclosure of its content }\end{array}$ & $\begin{array}{l}\text { 1. Generalization of the } \\
\text { real facts and phenomena. } \\
\text { 2. Work with drawings } \\
\text { and moving models. } \\
\text { 3. Doing constructions, } \\
\text { calculations. }\end{array}$ & $\begin{array}{l}\text { 4. Doing laboratory and } \\
\text { practical work. } \\
\text { 5. Showing necessity for } \\
\text { doing tasks. } \\
\text { 6. Historical information. } \\
\text { 7. Showing imperfection } \\
\text { the acquired notions. }\end{array}$ & $\begin{array}{l}\text { 8. Using generalizations } \\
\text { and analogies to the } \\
\text { previous material. } \\
\text { 9. Showing necessity for } \\
\text { further expansion of } \\
\text { material. } \\
\begin{array}{l}\text { 10. Carrying out mini- } \\
\text { researches. }\end{array}\end{array}$ \\
\hline $\begin{array}{l}\text { Working with the } \\
\text { theorem formulation, the } \\
\text { analysis of its content and } \\
\text { structure }\end{array}$ & $\begin{array}{l}\text { 1. Formulation of the } \\
\text { theorem with support of } \\
\text { the drawing. } \\
\text { 2. Recognition of the } \\
\text { situations satisfying the } \\
\text { theorem conditions. } \\
\text { 3. Pupils' examples of } \\
\text { such situations. }\end{array}$ & $\begin{array}{l}\text { 4. Defining the structure } \\
\text { of the theorem. } \\
\text { 5. Formulation "in their } \\
\text { own words". } \\
\text { 6. Formulation of return, } \\
\text { opposite and contra } \\
\text { positive theorems. } \\
\text { 7. Filling the gaps in the } \\
\text { definition. }\end{array}$ & $\begin{array}{l}\text { 8.Giving counter } \\
\text { examples. } \\
\text { 9. The reformulation in } \\
\text { terms of another } \\
\text { "mathematical language". } \\
\text { 10. Search for mistakes in } \\
\text { the theorem definition. } \\
\text { 11. Giving a more precise } \\
\text { definition to the theorem. }\end{array}$ \\
\hline $\begin{array}{l}\text { Search for the proof of } \\
\text { the theorem and its } \\
\text { realization }\end{array}$ & $\begin{array}{l}\text { 1. Demonstration of the } \\
\text { main idea of the proof on } \\
\text { the basis of application of } \\
\text { visual and intuitive } \\
\text { means. } \\
\text { 2. Visualization of the } \\
\text { proof. }\end{array}$ & $\begin{array}{l}\text { 3. Acquaintance with the } \\
\text { proof method. 4. Stating } \\
\text { consequences from } \\
\text { theorem conditions, } \\
\text { selection of sufficient } \\
\text { conditions for } \\
\text { implementation of its } \\
\text { requirements. } \\
\text { Prompting the use of } \\
\text { heuristic methods while } \\
\text { searching for the proof. }\end{array}$ & $\begin{array}{l}\text { 6. Stating the alternative } \\
\text { directions while } \\
\text { searching for the proof. } \\
\text { 7.Expedient choice of } \\
\text { "proof language". } \\
\text { 8. "Brainstorming". }\end{array}$ \\
\hline $\begin{array}{l}\text { Fixing the theorem and } \\
\text { its proof }\end{array}$ & $\begin{array}{l}\text { 1. Proof reproduction } \\
\text { with use of visual aids. } \\
\text { 2. Stating the main stages } \\
\text { of the proof. } \\
\text { 3. Defining the main idea } \\
\text { of the proof. }\end{array}$ & $\begin{array}{l}\text { 4. Stating the steps of the } \\
\text { proof with justification. } \\
5 \text {. Reproduction of used } \\
\text { arguments. } \\
6 \text {. The proof according to } \\
\text { the changed drawing. } \\
\text { 7. Filling the gaps. }\end{array}$ & $\begin{array}{l}\text { 8. Proof denial. } \\
\text { 9.Creation of the } \\
\text { genealogical theorem. } \\
\text { 10.Application of some } \\
\text { other way of the proof. } \\
\text { 11.Stating "not quite } \\
\text { logical" moments and } \\
\text { their justification. }\end{array}$ \\
\hline $\begin{array}{l}\text { Application of theorems } \\
\text { and final explanation of } \\
\text { their value }\end{array}$ & $\begin{array}{l}\text { 1. Theorem application in } \\
\text { a standard situation. } \\
\text { 2. Stating rules of the } \\
\text { activity based on this } \\
\text { theorem. }\end{array}$ & $\begin{array}{l}\text { 3.Application in some } \\
\text { other situation. } \\
\text { 4.Application of the } \\
\text { acquired way of the } \\
\text { proof. } \\
\text { 5. Research of important } \\
\text { special cases. } \\
\text { 6.Stating direct } \\
\text { consequences from the } \\
\text { theorem and their proof. }\end{array}$ & $\begin{array}{l}\text { 7.Synthesis of the } \\
\text { theorem and its proof. } \\
\text { 8. Transfer of the theorem } \\
\text { and the way it is proved } \\
\text { in other sections. } \\
\text { 9. Logic experiment. }\end{array}$ \\
\hline
\end{tabular}


reasoning based on experience and is backed by models of pupils' academic work at this level. Finally, at the final stage of teaching reasoning the theorem proving should be taught at all levels. It should be stated that the theorem proving in the textbook is perceived at the highest level, and the third stage (unassisted reasoning in the minimized type) at the average level.

Such technology, as the school practice shows, allows to stimulate pupils wish to master logic rather than intuitive steps in reasoning, may guide pupils in their own search for future proofs of mathematical statements $[6,7,10]$. The strategy described was introduced in papers $[6,7]$ and implemented in the school course of Mathematics.

\section{References}

[1] I.S. Yakimanskaya, Characteristics of creative thinking of students, Russia, Moscow, Education, 1989.

[2] V. A. Dalinger, One method of prove. Mathematics at school, Russia, 1993, V.5, pp. 12-14.

[3] G.V. Dorofeev, The thesis about correctness of reasoning and details of presentation during task solving, Mathematics at school, Russia, 1982, V.1, pp. 44-47.

[4] J. Piaget, Judgment and Reasoning in the Child, Russia, St. Petersburg, Union, 1997.

[5] G. Polya, Mathematical Discovery: On Understanding, Learning and Teaching Problem Solving, Russia, Moscow, Science, 1976.

[6] M. Rodionov, Motivational Strategies for Teaching Math: theoretical aspects and practical implementation. Germany, Saarbrücken, LAP LAMBERT Academic Publishing Gmbh\& Co. KG, 2012.

[7] M. Rodionov, E. Marina, The formation of pupils thinking skills in construction problems-solving, Russia, Penza, PSPU, 2006.

[8] M. Rodionov, Z. Dedovets, Dynamic Peculiarities of the Establishment of Pupils' Valuable Attitude towards Mathematical Demonstrative Reasoning and their Application in School Practice. London International Conference on Education (LICE-2012) In Collaboration with World Congress on Sustainable Technologies (WCST-2012). Proceedings (November 19-22, 2012, London, GBR).- P.620-624.

[9] E.L. Thorndike The psychology of algebra. The Macmillan Company, New York, 1926

[10] Z.I. Slepkan, Teaching Proofs in Geometry, Russia, Moscow, High School, 1989, pp.34-43. 